Relations industrielles

Industrial Relations

\title{
"La qualification du travail », Bureau International du travail, Genève 1960, 172 pp.
}

\section{Jean-Paul Deschênes}

Volume 15, numéro 3, juillet 1960

URI : https://id.erudit.org/iderudit/1021974ar

DOI : https://doi.org/10.7202/1021974ar

Aller au sommaire du numéro

Éditeur(s)

Département des relations industrielles de l’Université Laval

ISSN

0034-379X (imprimé)

1703-8138 (numérique)

Découvrir la revue

Citer ce compte rendu

Deschênes, J.-P. (1960). Compte rendu de ["La qualification du travail », Bureau International du travail, Genève 1960, 172 pp.] Relations industrielles /

Industrial Relations, 15(3), 389-389. https://doi.org/10.7202/1021974ar

Tous droits réservés (C Département des relations industrielles de l’Université Laval, 1960
Ce document est protégé par la loi sur le droit d'auteur. L'utilisation des services d'Érudit (y compris la reproduction) est assujettie à sa politique d'utilisation que vous pouvez consulter en ligne.

https://apropos.erudit.org/fr/usagers/politique-dutilisation/ 
< La qualification du travail \$, Bureau International du travail, Genève 1960, 172 pp.

Dans un numéro précédent de la Revue, nous avions été très élogieux à l'égard d'un volume du B.I.T. et intitulé: «Introduction à l'Etude du Travail». C'est avec le même sentiment que nous présentons une nouvelle publication du B.I.T. : La qualification du travail.

Ce qui distingue ce volume d'autres du genre, c'est qu'il n'a pas pour but de vendre un produit quelconque. Avec un souci d'objectivité digne d'éloges, le B.I.T. analyse sans verbiage inutile le problème de l'heure dans nos usines et manufactures: la rémunération du travailleur.

Après avoir défini la qualification du travail et analysé la structure des salaires dans une entreprise, les auteurs exposent la façon de qualifier le travail dans les économies planifiées et dans un système de conventions collectives.

Le second chapitre discute des quatre principales méthodes d'évaluer les tâches, soit le Rangement, le Méthode des Classes, la Comparaison des facteurs et la Méthode des points, tout en faisant ressortir les avantages et les déavantages de chacunes de ces méthodes. Suit un chapitre portant sur quelques-uns des problèmes posés par les systèmes analytiques de qualification du travail.

Les chapitres quatrième et cinquième se distinguent nettement de la littérature courante sur l'évaluation des tâches et celte section du volume est à notre avis la partie la plus importante. En effet, dans le chapitre quatrième, on étudie d'assez près la mise en opération de systèmes d'évaluation des tâches dans diverses entreprises des Etats-Unis, de l'Allemagne occidentale et du Canada en recherchant les causes qui ont pu amener un échec et les facteurs qui ont pu contribuer à un succès. Le chapitre cinquième discute assez longuement des avantages et des inconvénients de la qualification du travail.

Nous ne pouvons que féliciter le B.I..T d'avoir publié un tel volume, succint mais complet; et tous ceux qui, de près ou de loin, sont intéressés à la rémunération du travailleur doivent lire attentivement ce volume. Il permettra de corriger bien des préjugés tant chez ceux qui voient dans l'évaluation des tâches une méthode scientifique inattaquable parce qu'une évaluation qualitative et exprimée avec des chiffres, que chez ceux qui rejettent tout système d'évaluation des tâches parce qu'ils n'en voient que les faiblesses et qu'ils préfèrent une détermination purement arbitraire des salaires, quelquefois dans l'espérance égoiste que leurs intérêts personnels soient mieux protégés, ceci au détriment de la majorité.

\section{Jean-Paul Deschenes}

\section{"Pour une économie du bien commun 》,} selon la doctrine sociale de l'Eglise, par Georges DUCOIN, Collection Théologie, pastorale, et spiritualité. Recherches et syntèses. P. Lethielleux, Editeur, 10, rue Cassette, Paris (VI), 1960 - 144 pp.

Les ouvrages sur la doctrine sociale de l'Eglise ne manquent pas. Beaucoup ont cependant une valeur discutable, soit que les auteurs se bornent à répéter des lieux communs, soit qu'il leur manque des connaissances de la réalité économico-sociale, soit qu'ils ne possèdent point le sens d'interprétation des documents pontificaux auxquels ils ne savent pas toujours accorder une juste appréciation.

«L'enseignement des théologiens est unanime: les Papes ne confèrent pas le même poids ni la même valeur à tous les documents qu'ils publient, $\mathrm{ni}$ à chaque phrase d'un même document, ni à toutes les paroles qu'ils prononcent. Ainsi, en ce qui concerne la doctrine sociale de l'Eglise, il existe toute une gamme, depuis l'ordre, le conseil, la suggestion, jusqu’à la simple réflexion... Puisque la doctrine sociale de l'Eglise est liée aux conditions concrètes de notre monde industriel, il va de soi qu'elle se développe comme ce monde. Incontestablement, les fondements dogmatiques sur lesquels repose la doctrine sociale de l'Eglise sont intangibles, tout autant que la doctrine chrétienne elle-même. De même les grands principes de cette doctrine sociale qui découlent immédiatement du dogme; ainsi le respect de la justice, la dignité de la personne humaine, etc. Par contre, comme la doctrine sociale va jusqu'à des applications concrètes, ces applications sont toujours données en fonction du contexte 